\title{
Educação e globalização: entre regulação e emancipação
}

Education and Globalization: Between Regulation and Emancipation

Éducation et globalisation: entre la régulation et l'émancipation

\section{Stephen R. Stoer}

\section{OpenEdition}

\section{Journals}

Edição electrónica

URL: http://journals.openedition.org/rccs/1254

DOI: $10.4000 /$ rccs. 1254

ISSN: 2182-7435

\section{Editora}

Centro de Estudos Sociais da Universidade de Coimbra

Edição impressa

Data de publição: 1 Outubro 2002

Paginação: 33-45

ISSN: 0254-1106

Refêrencia eletrónica

Stephen R. Stoer, "Educação e globalização: entre regulação e emancipação », Revista Crítica de Ciências Sociais [Online], 63 | 2002, colocado online no dia 01 outubro 2012, criado a 19 abril 2019 URL : http://journals.openedition.org/rccs/1254; DOI : 10.4000/rccs.1254 


\section{STEPHEN R. STOER}

Centro de Investigação e Intervenção Educativas (CIIE) da Faculdade de Psicologia

e de Ciências da Educação da Universidade do Porto

\section{Educação e globalização: entre regulação e emancipação*}

Neste artigo, retoma-se o trabalho publicado no livro Transnacionalização de Educação: da crise da educação à "educação" da crise, com o objectivo de o interrogar em três aspectos: 1) a utilização do conceito de transnacionalização no título (e não utilização, por exemplo, do conceito de globalização); 2) a concepção de mudança social que está subjacente à "crise da educação"; e 3) a relação, no livro, entre regulação e emancipação.

A minha intenção, com este artigo, não é tanto a de relatar o livro que escrevemos (Stoer, Cortesão e Correia, 2001), porque certamente muitos o irão ler, mas, antes, a de ir um pouco além dele e discutir algumas questões que, de um modo ou de outro, estão na base do texto e têm vindo a ser objecto de reflexões várias, sobretudo após a conclusão do trabalho. A primeira destas questões relaciona-se logo com o próprio título que foi dado ao livro.

\section{Porquê transnacionalização da educação e não educação e globalização?}

Em que sentido, ou até que ponto, é que pode falar-se da globalização da educação? Curiosamente, em todas as discussões que foram realizadas ao longo do projecto que esteve na origem do livro, nunca se relacionou explicitamente o conceito de transnacionalização com o conceito de globalização, embora se tivesse feito tal relacionamento de uma forma implícita no trabalho de Cortesão e Stoer (2001) publicado no livro Globalização: Fatalidade ou utopia? (Santos, 2001).

Num trabalho recente (Stoer e Cortesão, 1999), colocámos a questão: será que o ensino público é o último refúgio da resistência ao pro-

\footnotetext{
* Agradecimentos ao António Magalhães pela sua valiosa colaboração na produção deste texto.
} 
cesso de transnacionalização? Trata-se de um dos campos que mais resistência tem mostrado face aos processos de globalização? A pergunta coloca-se perante a defesa por conhecidos políticos da educação em Portugal de que

a educação é o mecanismo privilegiado para a preservação e afirmação da identidade nacional, para a transmissão de valores éticos e cívicos e para a formação dos recursos humanos necessários para enfrentar o desafio do desenvolvimento económico e da modernização da sociedade. (Grilo et al., 1992: 11)

Sustentámos no referido trabalho que a resposta à pergunta passava pela consideração da realidade da escola pública na semiperiferia: isto é, a renovação e a promoção do progresso da nação portuguesa passa tanto pela "preservação e afirmação da identidade nacional" através da educação como pela desconstrução "das características tradicionais e muito persistentes que têm bloqueado as nossas possibilidades de modernização", nas palavras de Ernani Lopes et al. num livro que teve bastante impacto na altura da sua publicação (1989: 255). Por outras palavras, a modernização da sociedade portuguesa passaria pela internacionalização da sua economia, tendo aqui a educação também um papel importante a desempenhar. Em síntese, pode defender-se que o processo de modernização português, condicionado pela simultaneidade da crise e da consolidação da escolarização de massas, ${ }^{2}$ conduz simultaneamente à desconstrução da escolarização como preservação e afirmação da identidade nacional e à sua promoção nesses mesmos termos em ordem à preservação dos valores nacionais e cívicos.

Em segundo lugar, a globalização implica uma coerência interna que a transnacionalização não tem. Neste sentido, é interessante considerar as três seguintes posições. Eric Hobsbawm, citado no trabalho de Dale e Robertson (1997), considera que até aos anos 60 a economia mundial era internacional. A partir dos anos 60, esta economia tornou-se transnacional, significando que nesta altura existia um sistema de actividades económicas para o qual os Estados, os seus territórios e as respectivas fronteiras, não constituíam o enquadramento básico. Este novo enquadramento de transnacionalização era constituído por: i) a proliferação de empresas trans- ou multinacionais; ii) uma nova divisão internacional de trabalho; e iii) o aparecimento de financiamento off-shore. Manuel Cas-

\footnotetext{
2 A noção da simultânea crise e consolidação da escola de massas em Portugal encontra-se desenvolvida em Stoer e Araújo (2000).
} 
tells, num trabalho escrito em 1994, parece reforçar as palavras de Hobsbawm, embora empregue, em vez do termo transnacionalização, o termo globalização:

Embora os Estados-nação sejam ainda realidades fundamentais importantes quando se pensa em estruturas e processos económicos, o que é significativo é que a unidade de contabilidade económica, tal como o quadro de referência para as estratégias económicas, não pode já ser a economia nacional. [...] O que é novo [...] é que a economia nacional funciona agora como uma unidade da economia mundial. Neste sentido, não estamos a ver somente um processo de internacionalização da economia, mas um processo de globalização [...], isto é, a interpenetração de actividades económicas e das economias nacionais ao nível mundial. (Castells, 1994: 18-19, sublinhado meu)

No seu opus magnum de 1996, Castells distingue entre a economia mundial e a economia global, defendendo que esta última "é uma economia com a capacidade de trabalhar como uma unidade de tempo real numa escala planetária" (1996: 92). A nova infra-estrutura da economia global, afirma Castells, assenta nas tecnologias da informação e da comunicação.

Robert Cox, autor canadiano conhecido pelo seu trabalho sobre as organizações internacionais, também destaca a ideia da economia global. Num trabalho recente, Cox afirma que

esta crise surge como a consequência de uma transição de uma economia internacional para uma economia global. $\mathrm{Na}$ economia internacional, os Estados mantinham um grau importante de controlo sobre as suas economias nacionais e podiam regular a sua relação com a economia mundial exterior. As instituições de Bretton Woods foram concebidas como um meio de promover a cooperação entre Estados na realização dessa função reguladora. $\mathrm{Na}$ economia global emergente, esta capacidade autónoma dos Estados tem sido reduzida para todos os Estados, embora em maior grau para alguns. Os Estados são, pouco a pouco, reduzidos ao papel de ajustar as economias nacionais às dinâmicas da economia global desregulada. [...] [O Estado] prega que o mercado global desregulado é bom para toda a gente, embora alguns possam ser mais beneficiados do que outros. O Estado retém a função de tutela e de fiscalização dos contratos e dos instrumento de influência política para assegurar o acesso aos recursos e mercados mundiais [...], no entanto, pouco a pouco, o Estado é concebido como subordinado à economia. A competitividade na economia global é o critério último da política pública. (Cox, 1996: 104-5) 
No mesmo sentido de Cox, que introduz a importante questão dos mercados globais, Pierre Gonod e Philippe de la Saussay defendem que

a transição de transnacional para global implica a utilização de estratégias baseadas em duas tendências: o desaparecimento de fronteiras entre rumos diferentes de tecnologia através da emergência de tecnologias globais, genéricas e disseminadoras e, também, a redução de barreiras entre diferentes sectores de actividade através da emergência de mercados globais. (Gonod e Saussay, 1991: 5)

Pode defender-se que só muito recentemente é que estes mercados globais começaram a desenvolver-se no campo de educação.

Em terceiro lugar, torna-se importante, particularmente para a análise do campo educativo, fazer a distinção entre "mundialização" e "globalização". Esta distinção é desenvolvida no debate promovido por Roger Dale com os investigadores liderados por John Meyer da Universidade de Stanford, em torno da noção de "cultura educacional mundial comum" (CEMC) em contraste com a noção da "agenda de educação globalmente estruturada" (AEGE). No primeiro caso,

o desenvolvimento dos sistemas educativos nacionais e das categorias curriculares explica-se através de modelos universais de educação, de Estado e de sociedade, mais do que através de factores nacionais distintivos. (Dale, 2001: 135)

Esses modelos são baseados em valores ocidentais. O segundo caso

baseia-se em trabalhos recentes sobre economia política internacional [...] que encaram a mudança de natureza da economia capitalista mundial como a força directora da globalização e procuram estabelecer os seus efeitos, ainda que intensamente mediados pelo local, sobre os sistemas educativos. (ibid.: 135)

Assim, para Dale, é o imperativo económico que assume o papel principal no processo de globalização da educação e não as dimensões cultural e normativa (ver também Cortesão e Stoer, 2001).

Em síntese, a globalização da educação implica que no campo educativo se encontrem os efeitos: i) da interpenetração de actividades económicas e das economias nacionais ao nível mundial; ii) do desenvolvimento de mercados globais; e iii) de uma agenda de educação globalmente estruturada. No livro Transnacionalização da Educação, estão presentes o primeiro efeito (na segunda parte do livro) e o terceiro (em quase todos os capítulos do livro). Quanto aos mercados globais no campo de educação, voltaremos a este tema mais adiante. 


\section{Porque é que se fala, no subtítulo do livro, "da crise da educação à 'educação' da crise"?}

Em que é que consiste esta crise? A resposta vem no "Prefácio" do livro, onde se fala da crise de uma forma particular de educação, identificada normalmente com o modelo escolar desta que coincide com a transnacionalização da educação. A primeira parte do livro preocupa-se com a análise da crise, isto é, procura-se aí compreender a tensão que existe entre a crise e a consolidação da escola de massas em Portugal. Por um lado, através da análise de uma consolidação da escola de massas, num país da periferia da Europa, condicionada pela lenta transição de uma sociedade rural para uma sociedade urbana. Por outro lado, através da análise de um processo de erosão do modelo escolar onde o educativo é pensado sobretudo como oportunidade de acesso a uma cidadania de mercado.

A análise de alguns eixos da crise constitui a segunda parte do livro. Aí, abordam-se as novas formas da gestão da tensão que existe entre a simultânea crise e consolidação da escola de massas em Portugal. Defende-se que o reforço do papel da educação na regulação social tem um carácter eminentemente transnacional, como demonstra a própria noção de "sociedade do conhecimento", promovida pela ainda hesitante política educativa da União Europeia. Defende-se que esta transnacionalização constitui uma globalização de baixa intensidade do modo de regulação dominante nas políticas educativas, exemplificado pelos efeitos indirectos que sobre estas exercem os grandes projectos estatísticos internacionais, por um lado, e pelas relações entre as organizações internacionais e a formulação das políticas educativas nacionais, por outro. Aborda-se o novo papel (regulador e avaliador) do Estado através do estudo da criação em Portugal de uma rede nacional de Escolas Profissionais que, por sua vez, é indissociável da emergência de processos de construção de um referencial global europeu e da interpenetração das políticas educativas públicas nacionais e comunitárias. Este papel é também estudado através da abordagem da evolução do sistema de ensino superior, onde se encontra a atribuição de uma importância crescente à auto-regulação institucional e à empresarialização da educação.

$\mathrm{Na}$ terceira parte do livro, enuncia-se a possibilidade da "educação da crise" através: 1) do desenvolvimento de movimentos sociais novos (por exemplo, a educação inter/multicultural), cujo carácter é simultaneamente transnacional e local, e cuja natureza política é eventualmente capaz de denunciar os excessos de regulação da modernidade; 2) da colocação da hipótese de a educação poder estar imbuída de algumas características de 
lugar estrutural (o que é dependente de uma alteração paradigmática da educação formal para que, em vez de estar fundamentalmente informada de características de instituição da modernidade reguladora e transmissora de valores tradicionais, assuma as características de uma educação com preocupações emancipatórias - incluindo metodologias transgressivas, como, por exemplo, a investigação-acção); e 3) da radicalização mitigada - na semiperiferia - da contradição entre um conjunto de dispositivos tecnológicos emergentes em que não só o professor como também os espaços e os tempos da escola ficam condenados ao desaparecimento e o ressurgimento da escola reconfigurada como dispositivo estratégico de mobilidade social e de desenvolvimento das subjectividades.

Fala-se da "educação da crise" como se a crise da educação fosse "educável". Assim colocada, a questão da "educação da crise" emite o cheirinho de uma postura imbuída da imodéstia do intelectual na melhor tradição iluminista. Pelo menos é isto que agora sentimos. Noutro trabalho, precisamente para nos distanciarmos dessa atitude, defendemos que

na ausência das grandes narrativas, a mudança não se domina: "surfa-se", "pilota-se", ou "gere-se”. [...] O real é independente do sujeito que o conhece para acerca dele decidir, mas é também uma construção narrativa deste. A reflexividade não corresponde ao domínio cognitivo do real e da mudança, mas é antes uma possibilidade de lidar com a mudança. No final das grandes narrativas, a mudança poderá, pois, ser pilotada, surfada ou gerida mas nunca previamente estabelecida e direccionada. [...] As metáforas para designar a mudança não são já da ordem do espaço duro ( hard) (a roda da história, o controlo da natureza, o avanço do tempo, a colonização do futuro...), mas aquáticas, suaves ( $(s o f t)$ : ondas, fluxos e refluxos, voltas e reviravoltas... (Stoer, Cortesão e Magalhães, 1998: 213)

É esta distinção entre "dominar a mudança" e "gerir a mudança" que estrutura o distanciamento que agora, até certo ponto, sentimos quando nos confrontamos com a dicotomia presente no subtítulo "da crise da educação à 'educação' da crise”. Neste sentido, estamos de acordo com Tadeu da Silva quando, referindo o recente trabalho do sociólogo americano Popkewitz, afirma que "o que está em jogo (nesta época de grandes mudanças) não é apenas uma reestruturação neoliberal das esferas económica, social e política, mas uma reelaboração e redefinição das próprias formas de representação e significação social” (Silva, 1996: 246-47). Assim, a "educação da crise" (da educação) será sempre a sua gestão (ou "pilotagem" ou "surfagem") e nunca a sua dominação. 


\section{Educação e globalização: entre regulação e emancipação}

Nas considerações finais do livro Transnacionalização da Educação estão colocadas, de novo, as duas grandes questões acima referidas e que estruturam o conteúdo do livro: a questão da relação entre educação e regulação e a questão da relação entre educação e emancipação.

Quanto à primeira, a da relação entre educação e regulação, gostaríamos de retomar aqui o tema que acima referimos sobre a regulação da educação pelos mercados educativos.

Robertson, Bonal e Dale (2001) analisam o que designam por "GATS (General Agreement on Trade in Services - 1994 - da Organização Mundial de Comércio - OMC) e a indústria de serviços educativos". Defendem estes três autores que, no âmbito de GATS, a educação é reconceptualizada como uma empresa, isto é, os serviços educacionais são re-significados como trocáveis através do mercado. Hoje em dia, é difícil encontrar um sistema educativo público que não satisfaça as condições mínimas necessárias para ser coberto pela OMC - quer dizer, a existência de um mecanismo de mercado na maneira como os serviços de educação são apresentados ao público. A aplicação de GATS à educação parece implicar o seguinte: um quadro de obrigações (o que inclui, por exemplo, não discriminação no que diz respeito aos fornecedores nacionais e não discriminação entre outros membros/partes do acordo) e a aceitação da ideia da actividade educativa como uma mercadoria potencialmente susceptível de troca. Resumindo, se o GATS fosse, de facto, aplicado aos diferentes sectores da educação, o resultado seria o fim de uma série de barreiras que, neste momento, protegem a natureza da educação pública e a natureza pública da educação. Por outras palavras, o sector privado estaria em condições de minar o funcionamento público dos serviços educativos desafiando os monopólios governamentais. Concluem Robertson, Bonal e Dale que

[...] através de GATS estão criadas as condições para descontextualizar a actividade educativa da sua posição institucionalizada como bem público desmercadorizado, obrigando-a a assumir um lugar nos mercados globais (agora sujeita - pela adesão ao GATS - às novas regras de jogo). (2002: 15)

No fundo, trata-se, defendem os autores, de um processo complexo de reescalonamento e de reterritorialização da actividade educativa, de uma relocalização do próprio processo educativo. Este processo, que desloca, pelo menos em parte, a regulação do nível do Estado-nação para o nível supranacional, surge como uma característica central das implicações principais para o campo educativo do capitalismo flexível. 
Quanto à segunda questão, a da relação entre educação e emancipação, torna a colocar-se a questão da relação entre o sujeito e o real: emancipação quer dizer "dominar" ou "gerir" a mudança social?

Stephen Ball defende, num texto recente, que

[...] um fluxo instável, desigual, mas aparentemente imparável, de ideias de reforma intimamente relacionadas está a permear e a reorientar os sistemas educativos, com histórias muito diferentes e situados em locais social e politicamente diversos. (2001: 1)

Em contraste com a educação da tradição de bem-estar público centrado no Estado, esta educação desenvolve-se através de tecnologias políticas baseadas na trilogia "mercado, gestão e performatividade". Performatividade, sustenta Ball, é uma tecnologia, uma cultura e um modo de regulação. Neste sentido, as mais recentes reformas da educação constituem um processo de re-regulação, isto é, um veículo para a mudança social e cultural e, mais especificamente, mecanismos para reformar os agentes educativos. Assim, constituem um meio para alterar o que significa ser professor: o professor torna-se, diz Ball, num "sujeito empreendedor" ("an enterprising subject"), isto é, num gestor de performatividade. $\mathrm{Na}$ base deste processo está a mercadorização do conhecimento, no âmbito da qual "empenho, discernimento e autenticidade" são lidos através da performance. Ball pergunta: "será que a performatividade constitui um veículo para mudar a natureza do trabalho e aprendizagem académicas?", uma espécie de meta (ou grande) narrativa que (re)define e, através das políticas que inspira e legitima, constrange toda uma variedade de relações dentro de e entre Estado, sociedade civil e economia?

Os argumentos de Ball encontram eco no trabalho de Basil Bernstein (1996; ver também 2000) sobre o que este último designa a Sociedade Totalmente Pedagogizada (STP). Bernstein pergunta o que acontece com as modalidades pedagógicas quando a sua base social muda. Por outras palavras, o que é que significa para a pedagogia o desenvolvimento do capitalismo flexível? (Já vimos acima as suas implicações para a reconceptualização da educação pública.) E responde que tem havido uma mudança de um modelo de pedagogia baseado na competência, dominante a partir dos anos 50, para um modelo de pedagogia baseado na performance, dominante a partir dos anos 80 (Bernstein, 1996). O primeiro caracterizou-se por ser uma medida importante de controlo por aquele que aprende sobre a selecção, sequência e ritmo do processo de aprendizagem e era baseado em regras de 
reconhecimento e realização implícitas (isto é numa "pedagogia invisível") em que todas as pessoas eram consideradas inerentemente competentes (Bernstein fala da competência linguística de Chomsky, da competência cognitiva de Piaget, da competência cultural de Lévi-Strauss, da competência prática de Garfinkel, da competência comunicativa de Dell Hymes). O segundo modelo coloca a ênfase no output específico daquele que aprende e nas capacidades necessárias para a produção desse output (texto, produto) específico.

Aqui é preciso fazer uma distinção entre uma "pedagogia visível" baseada em regras de reconhecimento e realização explícitas (pedagogia normalmente identificada com a dominação do sistema educativo por aquela classe que Bernstein designa por "antiga classe média" ${ }^{3}$ ) e aquilo que Bernstein designa por "performance genérica", baseada nos objectivos de formatividade, focalizada naquilo que acontece fora da escola e nos novos locais de recontextualização - significando que este modo de pedagogia é construído e distribuído no exterior e independentemente dos campos de recontextualização pedagógica. ${ }^{4}$ Por outras palavras, os objectivos de formatividade inerentes à "performance genérica" reconfiguram o local de recontextualização dando potencialmente lugar à dominação do espaço de recontextualização pedagógica (da ordem do local) pela recontextualização oficial (do Estado), reduzindo dessa forma a autonomia relativa da educação e assegurando o controlo - mesmo quando remoto - pelo Estado. A performance genérica requer uma modalidade pedagógica que prepara aquele que aprende para "o trabalho e a vida”, isto é, que está baseada numa identidade projectada "para fora" em vez de uma identidade virada "para dentro" e que concebe o trabalho e a vida na base do curto prazo (short-termism). Neste sentido, defende Bernstein, "aquele que aprende nunca saberá o suficiente e jamais desenvolverá todas as capacidades e competências necessárias” (apud Bonal, 2001).

A mudança de um modelo de competência para um modelo de performance, sustenta Bernstein, resulta do facto de que, no primeiro, o conheci-

\footnotetext{
3 Trata-se de uma classe média que se desenvolve nos países centrais entre o século XIX e o século XX, devido ao aumento da complexidade da divisão económica do trabalho, através de unidades de produção que se identificam com as empresas, com a indústria. A distinção entre "pedagogia visível" e "pedagogia invisível" encontra-se no trabalho de Bernstein (1977) e refere-se à maior ou menor distância entre os conteúdos disciplinares e ao maior ou menor grau de transmissibilidade presente no processo pedagógico. Isto é, uma pedagogia é tanto mais visível quanto mais fortes forem as fronteiras entre as disciplinas e quanto mais transmissiva for a pedagogia utilizada. ${ }^{4}$ Bernstein entende por campo de recontextualização pedagógica aquele espaço que gera os enquadramentos, as possibilidades e os próprios espaços da teoria pedagógica, da investigação sobre a educação e das práticas educativas.
} 
mento encontra-se ligado ao babitus (da nova classe média ${ }^{5}$ ) e não necessariamente ao "trabalho e à vida". Por outras palavras, no primeiro caso, o mercado só pode ter um impacto indirecto (e "invisível") sobre o quê, e como, se aprende na escola.

Designámos noutro trabalho (Magalhães e Stoer, 2002a) esta ideia de um conhecimento específico, virado para as necessidades do mercado, como throughput para caracterizar um conhecimento que passa simplesmente pelo indivíduo (como o dinheiro) colocando-o no mercado de trabalho sem minimamente o formar. Para assegurar esta reconfiguração do campo de recontextualização pedagógica, defende Bernstein (1996), o Estado fraco da economia global precisa de um Estado forte para o campo pedagógico. É assim que se assiste à intrusão de agências do Estado no campo pedagógico e à tentativa, pelo campo de recontextualização oficial, de colonizar o campo de recontextualização pedagógica. Pode defender-se que, desde os anos 80, em Portugal, tal como em Espanha (Bonal, 2001), este processo de colonização se tem realizado não na base de um modelo de performance mas, antes, na base de um modelo de competência. Eis a razão do recente clamor no sentido do desenvolvimento de um modelo de performance na educação portuguesa.

Para escapar às armadilhas que a noção de competência parece trazer consigo, temos vindo a analisar o debate sobre políticas educativas em Portugal evitando entrar na discussão acerca do carácter mais ou menos amplo, ou mais ou menos restrito, das competências a criar pelo processo de formação escolar. O preço a pagar por esse centramento do debate parece-nos ser o fechamento da discussão em torno do dilema das "boas" competências - que servem a formação integral do indivíduo - e das "más” competências - aquelas que, cativas do curto prazo, apenas capacitam para lidar com situações, frequentemente em contexto de empresa, pouco complexas e com necessidade de baixa qualificação. Em alternativa, temos procurado construir um continuum heurístico em que pedagogia e performance (Magalhães e Stoer, 2002a, 2002b) constituam os extremos. Ao colocarmos aí as diferentes propostas de mandato para o sistema educativo, a natureza política destas parece mais bem explicitada. Dado que não se pode ser idealista em relação aos efeitos exponencialmente selectivos do mercado de trabalho, e dado que o conhecimento veiculado no processo educativo não deve visar apenas a performance de cada um em contexto de trabalho, não opomos pedagogia às exigências de performance. Se é verdade, como lembram os

\footnotetext{
5 Nova classe média essa que, emergindo nos meados do século XX, se caracteriza pelo investimento no capital cultural e escolar - em detrimento, por exemplo, do investimento na propriedade como estratégia de classe.
} 
neomeritocratas mais assanhados, que a pedagogia sem performance não é "nada", também o parece ser que não há performance sem pedagogia, na medida em que, por mais mecânico que seja o conhecimento a veicular, ele é sempre "veiculado", quer dizer, mediado por um processo pedagógico.

Assim, a assunção daquele continuum não só permite fazer um levantamento das propostas dos diferentes intervenientes no debate, como também sugere que, no actual contexto de um mercado de trabalho estruturado pelo capitalismo flexível, não é obrigatório ficar confinado à defesa radicalmente pedagógica da educação (como se a autonomia do pedagógico fosse independência em relação à economia) ou à redução da educação à performance (como se a performance pudesse existir sem pedagogia). Os caminhos alternativos podem ser procurados nas diferenças (eventualmente incomensuráveis) que estruturam os mandatos educativos e na sua mútua análise crítica.

Tanto mais que a escola deixou de ser percepcionada pelas famílias e pelos alunos/estudantes como $o$ recurso de formação e, logo, de criação de competências. Outras organizações e instituições, públicas e privadas, assim como os mais diversos contextos proporcionam formação e qualificam os que neles se envolvem. Empresas, associações, movimentos sociais, políticos, religiosos e a própria família, etc., apresentam-se já explicitamente em alguns países como alternativas à escola pública. A escola deixou de ser a instituição socializadora central e as narrativas educacionais legitimadoras da missão quase redentora (a formação do homem novo, do indivíduo-cidadão) que o projecto da modernidade lhe atribuía parecem viver apenas em alguns e excepcionais lugares e na mente generosa de alguns estóicos educadores. A instituição e os serviços que ela presta são, antes, integradas nas estratégias que os indivíduos vão reflexivamente construindo.

Numa sociedade totalmente pedagógica, a educação escolar parece ter muita da sua relevância bastante confinada à função de acreditação, de atribuição de diplomas. Como consequência da crescente reflexividade social e individual, é a escola que é colocada nos guiões que os indivíduos fazem para a sua vida e não ao contrário, como de alguma forma sonharam muitos pedagogos modernos (isto é, a escola forneceria o "bom" material com o qual os indivíduos construiriam a sua vida). Segundo Ulrich Beck (1992), a capacidade para cada um escolher, manter e justificar as suas próprias relações sociais e opções de vida não é a mesma em e para todos, ela é,

como qualquer sociólogo das classes sabe, uma capacidade aprendida que depende das origens sociais e familiares especiais. A conduta reflexiva da vida, o planeamento que cada um faz da sua biografia e das relações sociais, dá origem a uma nova desigualdade, a desigualdade no lidar com a insegurança e a reflexividade. (Beck, 1992: 98) 
A escolarização surge, neste contexto, a um mesmo tempo, como um instrumento a utilizar para escapar às "origens sociais e familiares" e como consequência dessas mesmas origens.

Para concluir, esta espécie de releitura do livro Transnacionalização da Educação: da crise da educação à "educação" da crise termina "entre regulação e emancipação". Com isto, pretende-se sublinhar duas coisas: por um lado, assinalar o facto de a relação entre educação e regulação estar em vias de se alterar significativamente como resultado da globalização da educação (os efeitos dos mercados globais sobre a educação prometem aprofundar-se nos tempos que vêm); por outro lado, destacar o facto da aparente existência de uma nova relação entre educação e emancipação (a "educação" da crise da educação será sempre, no máximo, a sua gestão e nunca a sua dominação). Reconhece-se também, e em síntese, que a regulação e a emancipação constituem os dois pólos de um continuum que, por sua vez, potencialmente produz leituras várias e diversificadas do fenómeno de globalização. As implicações destas novas relações já estão a ser sentidas nas políticas educativas portuguesas, quer no que diz respeito à sua produção, quer em relação à sua análise. Neste sentido, o livro Transnacionalização da Educação não é mais do que um dos pontos de partida.

\section{Referências Bibliográficas}

Ball, Stephen (2001), «Reforming Schools/Reforming Teachers and the Terrors of Performativity», comunicação ao 2. ${ }^{\circ}$ Congresso Português e Brasileiro sobre Política Educativa e Administração.

Beck, Ulrich (1992), Risk Society. London: Sage.

Bernstein, Basil (1977), Class, Codes and Control, Volume 3. London: Routledge \& Kegan Paul.

Bernstein, Basil (1996), Pedagogy, Symbolic Control and Identity. London: Taylor \& Francis.

Bernstein, Basil (2000), «Das pedagogias aos conhecimentos», Educação, Sociedade $\mathcal{E}$ Culturas, 15, 9-17.

Bonal, Xavier (2001), «Captured by the Totally Pedagogised Society: Teachers and Teaching in the Knowledge Economy», texto policopiado.

Castells, Manuel (1994), «Paths Towards the Informational Society: Employment Structure in G-7 Countries, 1920-1990», International Labour Review, 133(1), 5-33 (com Yoko Aoyama).

Castells, Manuel (1996), The Rise of the Network Society. Malden, Mass.: Blackwell. 
Cortesão, Luiza; Stoer, Stephen R. (2001), «Cartografando a transnacionalização do campo educativo: O caso português», in Boaventura de Sousa Santos (org.), 369-406.

Cox, Robert (1996), Approaches to World Order. Cambridge: Cambridge UP.

Dale, Roger (2001), «Globalização e educação: Demonstrando a existência de uma 'Cultura Educacional Mundial Comum' ou localizando uma 'Agenda Globalmente Estruturada para a Educação'?», Educação, Sociedade \& Culturas, 16, 133-170.

Dale, Roger; Robertson, Susan (1997), «Resisting the Nation, Reshaping the State: Globalisation Effects on Education Policy in New Zealand», in Mark Olssen; Kay Morris Mathews (orgs.), Education Policy in New Zealand. Palmerston North: Dunmore, 209-227.

Gonod, Pierre F.; Saussay, Philippe de la (1991), Europe: Province of the World, Relatório para Europrospective II, Namur, 10-12 de Abril.

Grilo, E. Marçal; Emídio, M. Tavares; Silva, J J. R. Fraústo da (1992), «Algumas considerações sobre as reformas da educação», Colóquio Educação e Sociedade, 1, 11-27.

Lopes, Ernâni R. et al. (1989), Portugal, o desafio dos anos 90. Lisboa: Presença.

Magalhães, António M.; Stoer, Stephen R. (2002a), A escola para todos e a excelência académica. Porto: Profedições.

Magalhães, António M.; Stoer, Stephen R. (2002b), «A nova classe média e a reconfiguração do mandato endereçado ao sistema educativo», Educação, Sociedade E Culturas, 18 (no prelo).

Robertson, Susan; Bonal, Xavier; Dale, Roger (2001), «GATS and the Education Service Industry: The Politics of Scale and Global Re-Territorialization», Comparative Education Review (no prelo).

Santos, Boaventura de Sousa (org.) (2001), Globalização: Fatalidade ou utopia?. Porto: Afrontamento.

Silva, Tomaz Tadeu da (1996), «O adeus às metanarrativas educacionais», in T. T. da Silva (org.), Identidades terminais. Petrópolis: Vozes, 236-250.

Stoer, Stephen R.; Araújo, Helena Costa (2000), Escola e aprendizagem para o trabalho num país da (semi)periferia europeia. Lisboa: Instituto de Inovação Educacional.

Stoer, Stephen R.; Cortesão, Luiza (1999), "Levantando a Pedra". Da pedagogia inter/ multicultural às políticas educativas numa época de transnacionalização. Porto: Afrontamento.

Stoer, Stephen R.; Cortesão, Luiza; Correia, José Alberto (orgs.) (2001), Transnacionalização da educação: Da crise da educação à 'educação' da crise. Porto: Afrontamento.

Stoer, Stephen R.; Cortesão, Luiza; Magalhães, António M. (1998), «A questão da impossibilidade racional de decidir e o despacho sobre os currículos alternativos», in Albano Estrela; Júlia Ferreira (orgs.), A decisão em educação. Lisboa: AFIRSE, 201-215. 